\title{
Estabilidade de extrato de tomate em embalagens metálicas com baixo revestimento de estanho
}

\author{
Stability of canned tomato concentrate in metal packaging \\ with reduced tin layer
}

\section{Autores | Authors}

凶 Sílvia Tondella DANTAS

Instituto de Tecnologia de Alimentos (ITAL/CETEA)

Av. Brasil, 2880 CEP: $13070-178$

Campinas/SP - Brasil e-mail: silviatd@ital.sp.gov.br

Jozeti Barbuti GATTI
Fiorella Balardin Hellmeister
DANTAS
Elisabete Segantini SARON
Paulo Henrique Massaharu

KIYATAKA

Instituto de Tecnologia de Alimentos (ITAL/CETEA) Campinas/SP - Brasil

e-mail: jozeti@ital.sp.gov.br e-mail: fiorella@ital.sp.gov.br e-mail: esaron@ital.sp.gov.br e-mail:paulok@ital.sp.gov.br

Autor Correspondente / Corresponding Author

Recebido / Received: 10/06/2009 Aprovado / Approved: 04/06/2012 Publicado / Published: set./2012

\section{Resumo}

Este estudo teve por objetivo avaliar o desempenho de latas de três peças eletrossoldadas, com corpo produzido em folha de flandres com camada de estanho de 2,0 g.m- $\mathrm{m}^{-2}$ no lado interno, contendo $350 \mathrm{~g}$ de extrato de tomate; o material dessa lata é uma alternativa à folha comumente utilizada no Brasil para acondicionamento de extrato de tomate, com 2,8 g de Sn. $\mathrm{m}^{-2}$. As latas contendo o produto foram condicionadas a $35^{\circ} \mathrm{C}$ pelo período de 24 meses. Durante a estocagem, foram realizadas avaliações periódicas, incluindo determinações de estanho, ferro e cromo no alimento, pressão interna, composição gasosa do espaço livre e avaliação da aparência da superfície interna da embalagem, com o objetivo de se verificar a interação embalagem-alimento. Após o período estudado, pôde-se concluir que essa embalagem é uma opção viável para 13 meses de estocagem do produto, à temperatura ambiente de até $35^{\circ} \mathrm{C}$.

Palavras-chave: Lata de folha de flandres; Camada de estanho; Extrato de tomate; Ferro; Estanho; Cromo.

\section{Summary}

The performance of three piece welded cans produced in tinplate with an internal tin layer of $2.0 \mathrm{~g} \cdot \mathrm{m}^{-2}$, containing $350 \mathrm{~g}$ of tomato concentrate, as an alternative to the sheet normally used for tomato concentrate in Brazil, presenting $2.8 \mathrm{~g} \mathrm{Sn} . \mathrm{m}^{-2}$, was evaluated. The filled cans were conditioned at a temperature of $35^{\circ} \mathrm{C}$ for 24 months. The tin, iron and chromium contents of the product, can internal pressure and headspace gas composition were determined periodically, as well as a visual evaluation of the appearance of the internal surface of the can, in order to monitor package/food interactions. After completing the storage period it was concluded that such cans were a viable option for 13 months of storage of the product at an ambient temperature of up to $35^{\circ} \mathrm{C}$.

Key words: Tinplate Can; Tin layer; Tomato concentrate; Iron; Tin; Chromium. 


\section{Introdução}

A folha de flandres foi o primeiro material a ser utilizado na fabricação de embalagens metálicas, cuja aplicação data do século XVIII. A folha de flandres é constituída por um aço de baixo teor de carbono revestido, em ambas as faces, com uma camada de estanho metálico e uma fina camada de compostos de óxido de cromo, protegida por uma película de óleo lubrificante. Esse material combina a resistência mecânica e a capacidade de conformação do aço com a resistência à corrosão, a soldabilidade e a boa aparência do estanho (DANTAS, 1999).

As interações embalagem-alimento são as principais causas de alteração dos produtos enlatados e, em alguns casos, a velocidade de corrosão da embalagem é o fator determinante da vida útil do produto (DANTAS, 1999); essa corrosão é caracterizada principalmente pela perda de vácuo em razão da formação de hidrogênio e da dissolução dos metais que constituem a embalagem - ferro e estanho, quando do uso de folhas de flandres, e ferro e cromo, quando do uso de folhas cromadas -, o que pode levar a uma alteração das características sensoriais do produto e determinar a sua vida-de-prateleira (SARON et al., 2006).

A dissolução de ferro, cromo e estanho depende dos seguintes aspectos: composição do alimento, acidez, presença de oxidante (antocianinas, nitrato e cobre), presença de oxigênio no espaço livre, tempo e temperatura de estocagem (PERRING e BASICDVORZAK, 2002).

Em função do caráter ácido do extrato de tomate, da adição de cloreto de sódio, da presença de pigmentos naturais e da eventual presença de nitrato, o extrato de tomate apresenta características agressivas ao material metálico, requisitando uma adequada especificação de envernizamento interno, principalmente do side stripe, para manutenção das propriedades sensoriais e garantia da vida-de-prateleira desse produto.

Razões econômicas e ambientais, com base nos princípios de redução do consumo de recursos naturais, vêm direcionando vários estudos, como da otimização de embalagens. Saron et al. (2006) avaliaram a viabilidade do uso de folha de flandres com menor revestimento nominal de estanho para suco de maracujá pronto para o consumo. No estudo, foram avaliadas latas de três peças eletrossoldadas, produzidas com corpo em folha de flandres com camada nominal de estanho de 2,0 g. $\mathrm{m}^{-2}$, fundo em folha cromada e tampa em alumínio, em três opções de envernizamento interno. Como resultado, foi verificado que a embalagem metálica apresentou desempenho adequado para o acondicionamento do produto por 12 meses, indicando a viabilidade da redução da camada de estanho também para essa aplicação.
A avaliação de palmito pupunha acondicionado em latas com diferentes camadas nominais de estanho demonstrou que embalagens com menor revestimento (2,8 g Sn. $\left.\mathrm{m}^{-2}\right)$ apresentaram desempenho superior quanto à qualidade sensorial do produto em relação a embalagens de maior revestimento nominal de estanho (5,6 g Sn. $\left.\mathrm{m}^{-2}\right)$ (FARIA, 2000).

Dantas et al. (2000) também avaliaram a possibilidade da utilização da folha de flandres, com camada de estanho de 2,0 g. $\mathrm{m}^{-2}$ e envernizamento interno, no acondicionamento de palmito e concluíram que, além do revestimento de estanho, a película e a qualidade do verniz aplicado são fatores decisivos na definição dos mecanismos e velocidades dos processos decorrentes da interação lata-produto. Ao compararem esse revestimento com outros (2,8 e 5,6 g Sn.m-2), concluíram que a utilização de folhas de flandres com menores camadas de estanho de corpo é possível, desde que seja garantida uma proteção eficiente na costura lateral eletrossoldada.

Ao longo dos anos, a redução da camada de estanho também ocorreu nas latas de extrato de tomate. Inicialmente, o produto era acondicionado em folhas de flandres de alta estanhagem $\left(11,2 \mathrm{~g} \cdot \mathrm{m}^{-2}\right)$ sem envernizamento interno. A partir dos desenvolvimentos dos revestimentos orgânicos das embalagens metálicas, o revestimento de estanho foi progressivamente reduzido para 2,8 g.m-2. Até 2007, o extrato de tomate era acondicionado em latas de três peças envernizadas, com corpo em folha de flandres com camada de estanho interna de 2,8 g.m.-2 e tampa e fundo em folha cromada.

A Resolução RDC n 20 de 22 de março de 2007, publicada pela Agência Nacional de Vigilância Sanitária (ANVISA) do Ministério da Saúde, regulamentou o uso de embalagens, revestimentos, utensílios, tampas e equipamentos metálicos em contato com alimentos, internalizando a Resolução GMC n 46/06 do MERCOSUL, e autorizou o uso de diferentes camadas nominais de estanho aplicadas internamente na folha de flandres para contato direto com alimentos em geral, para uso com ou sem revestimento interno, desde que a embalagem cumpra com sua função tecnológica (BRASIL, 2007). Essa Resolução alterou a legislação anteriormente em vigor, que estabelecia o limite mínimo de 2,8 g.m-2 para o revestimento de estanho na face interna de latas para contato com alimentos. Dessa forma, tornou-se necessária a realização de estudos de estabilidade para verificar se a camada de estanho empregada na embalagem é adequada para o uso pretendido. Assim, as informações obtidas neste estudo serão utilizadas como subsídio técnico para evidenciar as condições reais de desempenho da lata de folha de flandres com revestimento interno de estanho de $2,0 \mathrm{~g} \cdot \mathrm{m}^{-2}$, envernizada 
internamente, no atendimento das funções tecnológicas previstas para o acondicionamento de extrato de tomate.

\section{Material e métodos}

\subsection{Embalagens}

Foram avaliadas latas de três peças eletrossoldadas, diâmetro $73 \mathrm{~mm}$, produzidas com corpo em folha de flandres com revestimento interno de $2,0 \mathrm{~g}$ de estanho por $\mathrm{m}^{2} \mathrm{e}$ tampa e fundo em folha cromada, envernizadas, acondicionando $350 \mathrm{~g}$ de extrato de tomate tradicional. Para a comparação do desempenho, utilizou-se uma lata de mesma marca comercial do produto, com a mesma capacidade e o mesmo sistema de envernizamento interno, porém produzida com folha de flandres de camada nominal 2,8 g. $\mathrm{m}^{-2}$, adquirida no mercado, identificada como lata referência. Essa embalagem foi estocada à temperatura ambiente, reproduzindo a condição normal de uso, e foi avaliada quando do término do seu prazo de validade em relação ao vácuo, à aparência interna e à concentração de ferro, estanho e cromo. Tal avaliação objetivou disponibilizar dados de concentração de metais e de aparência da superfície interna de lata de uso comercial, cuja diferença em relação à lata em estudo restringia-se ao revestimento de estanho do corpo, de forma a comparar os resultados obtidos para a lata em avaliação com os apresentados no produto disponível no mercado no término de seu prazo de validade.

\subsection{Teste de estocagem}

As latas em estudo foram condicionadas em câmara a $35^{\circ} \mathrm{C} \pm 2{ }^{\circ} \mathrm{C}$, sendo as avaliações realizadas logo após o recebimento (zero dia) e após 90, 180, 270, 365, 450, 540, 630 e 720 dias de estocagem. Em razão de problema analítico, a determinação do volume e da composição gasosa do espaço livre foi realizada no período de 810 dias, após o prazo inicialmente estabelecido.

\subsection{Caracterização das embalagens}

As latas foram caracterizadas quanto aos seguintes aspectos: revestimento de estanho na face interna, camada de passivação, avaliação das recravações de tampa e fundo e envernizamento (identificação, camada seca, aderência, grau de cura e porosidade), conforme descrito em Dantas et al., 1996. Foram utilizadas latas vazias e tampas avulsas, sem uso, pertencentes ao mesmo lote de produção das latas com produto.

\subsubsection{Camada de estanho ou de cromo do material metálico}

A camada de estanho total da face interna da folha de flandres do material do corpo das latas foi determinada pelo método coulométrico em sistema de potenciostato/ galvanostato EG\&G modelo 273, operando por meio do programa EG\&G 354. Nos materiais da tampa e do fundo, a camada de cromo óxido foi determinada por método colorimétrico, segundo a norma ISO 11950 (ISO, 1995), e a de cromo metálico, pelo método coulométrico, utilizando-se o mesmo sistema descrito anteriormente.

\subsubsection{Camada seca de verniz}

A camada seca foi determinada no verniz interno de corpo, tampa, fundo e região de soldagem das latas por método gravimétrico, utilizando-se balança Metller Toledo modelo AT $400 \mathrm{com}$ resolução de $10^{-4} \mathrm{~g}$ A remoção do revestimento foi conduzida mecanicamente, com auxílio de solvente.

\subsubsection{Aderência de verniz}

A aderência do verniz interno de corpo, tampa, fundo e região de soldagem foi determinada por meio de ensaio de fita adesiva em grade de $6 \mathrm{~cm} \times 6 \mathrm{~cm}$ em ângulo reto e espaçado por $1 \mathrm{~mm}$, conforme descrito na norma ASTM D 3359-08 (ASTM, 2008b).

\subsubsection{Identificação do verniz}

O envernizamento interno de corpo, tampa, fundo e região de soldagem foi identificado por meio de espectroscopia de infravermelho em equipamento marca Perkim Elmer modelo FTIR 1600. Realizou-se a análise direta do filme destacado do substrato em processo catódico ou pelo contato com ácido clorídrico.

\subsubsection{Grau de cura de verniz}

O grau de cura do verniz interno foi realizado pelo método de dissolução com solvente, contabilizando-se os ciclos de fricção de um acessório com $1 \mathrm{~kg}$ de massa até que a remoção do verniz fosse iniciada. Os resultados também foram confirmados pelo teste de absorção do corante violeta de metila.

\subsubsection{Porosidade de verniz}

A porosidade do verniz interno foi determinada na lata, formada pelo corpo e pelo fundo, incluindo a região da costura lateral eletrossoldada ( side stripe), e na tampa, separadamente. Foi aplicado o método eletroquímico, em equipamento WACO - Wilkens Anderson Co, usando-se solução de sulfato de sódio a 0,2\% acrescida de $0,1 \%$ de agente umectante como eletrólito. A região em que ocorre a descontinuidade foi identificada por meio da inversão da polaridade.

\subsubsection{Avaliação da recravação da tampa e do fundo}

Aplicou-se o procedimento de avaliação da seção transversal utilizando-se um sistema de análise 
de imagem My Scope da NPW Technical Laboratory Co, LTD, munido de câmera, lente de aumento de 90 vezes, monitor de vídeo e acessório para análise dimensional. Foram tomadas duas seções transversais separadas por $120^{\circ}$, sendo a primeira distante cerca de $2 \mathrm{~cm}$ da costura lateral. As medições de profundidade do rebaixo, da espessura da recravação e da espessura das folhas de corpo e tampa/fundo foram realizadas utilizando-se um relógio comparador Mitutoyo com ponta de agulha e resolução de $10^{-2} \mathrm{~mm}$, um micrômetro para recravação Starret com resolução de $10^{-2} \mathrm{~mm}$ e um micrômetro digital de ponta esférica Mitutoyo com resolução de $10^{-3} \mathrm{~mm}$, respectivamente.

\subsection{Avaliação visual interna da lata}

A avaliação visual foi realizada na face interna das latas, a olho nu, objetivando a verificação da ocorrência de corrosão ou outra alteração que porventura existisse. A intensidade de oxidação foi classificada pela comparação com a escala G da norma ASTM D610-08 (ASTM, 2008a).

\subsection{Quantificação de ferro, estanho e cromo no produto}

Os teores de ferro, estanho e cromo foram determinados no extrato de tomate pelo método de digestão por via úmida em sistema aberto, com a utilização de ácido clorídrico concentrado e aquecimento em chapa elétrica. Após o tratamento, os teores de ferro, estanho e cromo foram quantificados por espectrometria de emissão atômica induzida por plasma com detector óptico - ICP-OES, utilizando-se um equipamento Perkin Elmer, modelo OPTIMA 2000 DV, empregando-se curvas de calibração apropriadas para as análises.

As condições operacionais do ICP-OES estão descritas na Tabela 1.

Tabela 1. Condições de operação do ICP-OES.

\begin{tabular}{lc}
\multicolumn{1}{c}{ Potência } & $\mathbf{1 5 0 0 ~ W}$ \\
Vista & Axial \\
Fluxo do gás do plasma & 15 L.min . $^{-1}$ \\
Fluxo auxiliar & $0,2 \mathrm{~L} \cdot \mathrm{min}^{-1}$ \\
Nebulizador & Cross Flow \\
Fluxo de nebulização & 0,55 L.min ${ }^{-1}$ \\
Linhas de emissão (nm) & Sn 189,927; Fe 238,204; \\
& Cr 267,716 \\
\hline
\end{tabular}

\subsection{Determinação do volume e da composição gasosa de oxigênio $\left(\mathrm{O}_{2}\right)$, dióxido de carbono $\left(\mathrm{CO}_{2}\right)$, nitrogênio $\left(\mathrm{N}_{2}\right)$ e hidrogênio $\left(\mathrm{H}_{2}\right)$ do espaço livre}

O gás do espaço livre foi coletado por um funil e transferido para uma proveta graduada para a leitura direta do volume. As composições gasosas nas épocas zero dia e após 810 dias de estocagem foram determinadas em cromatógrafo a gás Shimadzu, modelo 14A, operando com detetor de condutividade térmica equipado com coluna Porapak-N e Peneira Molecular 13X, e cromatógrafo SRI Instruments, modelo $8610 \mathrm{C}$, equipado com coluna Porapak-N e MS 5A, respectivamente.

\subsection{Determinação do vácuo/pressão positiva}

Determinou-se o vácuo ou a pressão positiva por meio de manovacuômetro Ashcroft com resolução de 1,0 pol Hg para vácuo e de 0,5 psi para pressão positiva ou manovacuômetro digital Zürich, modelo Z-10-B, com resolução de 0,01 psi para vácuo e pressão positiva, após o condicionamento das latas a $23^{\circ} \mathrm{C}$ por no mínimo 8 horas.

\subsection{Análise estatística dos resultados}

Os resultados de volume e composição gasosa do espaço livre, de vácuo e de metais em cada período de estocagem foram submetidos à análise de variância a um critério de classificação e comparação das médias pelo teste da mínima diferença significativa, utilizando-se o programa Statistica, versão 5.0 (STATSOFT, 1995).

\section{Resultados e discussão}

\subsection{Caracterização da lata}

\subsubsection{Camada de estanho}

A camada de estanho do corpo da lata avaliada, expressa em média \pm desvio padrão, foi de 2,08 g.m $\mathrm{m}^{-2} \pm 0,12 \mathrm{~g} \cdot \mathrm{m}^{-2} \mathrm{e}$ as camadas de óxido de cromo para cada face da tampa e do fundo foram de $8,3 \mathrm{mg} \cdot \mathrm{m}^{-2} \pm 1,5 \mathrm{mg} \cdot \mathrm{m}^{-2}$ e de $8,2 \mathrm{mg} \cdot \mathrm{m}^{-2} \pm 0,8 \mathrm{mg} \cdot \mathrm{m}^{-2}$, respectivamente; as camadas de cromo metálico para cada face da tampa e do fundo foram de $69,0 \mathrm{mg} \cdot \mathrm{m}^{-2} \pm 0,8 \mathrm{mg} \cdot \mathrm{m}^{-2} \mathrm{e}$ de $72,6 \mathrm{mg} \cdot \mathrm{m}^{-2} \pm 14,9 \mathrm{mg} \cdot \mathrm{m}^{-2}$, respectivamente.

A folha de flandres do corpo das latas atendeu ao limite mínimo de estanho estabelecido para o valor nominal de $2,0 \mathrm{mg} \cdot \mathrm{m}^{-2} \mathrm{e}$ a folha cromada da tampa e do fundo, aos limites mínimos e máximos de cromo metálico e óxido de cromo estabelecidos para esses materiais na norma NBR 6665 (ABNT, 2010).

\subsubsection{Avaliação do envernizamento}

A lata apresentava verniz epóxi fenólico no corpo (aplicado em duas camadas, confirmadas pela visualização na sua remoção), na tampa, no fundo e no side stripe. A Tabela 2 apresenta os resultados da 
avaliação do envernizamento da face interna da lata de extrato de tomate.

Os parâmetros de avaliação da qualidade do verniz mostraram-se compatíveis com esse tipo de embalagem. A principal região de porosidade de verniz interno da lata foi a costura eletrossoldada, a qual apresentou muitos poros em toda a sua extensão.

\subsubsection{Avaliação da recravação da tampa e do fundo}

Os valores médios dos parâmetros dimensionais críticos de recravação, além da ausência de defeitos visuais, foram atendidos tanto na recravação da tampa como do fundo.

\subsection{Avaliação visual interna da lata}

A avaliação visual das latas de extrato de tomate nos diferentes períodos de análise na estocagem a $35^{\circ} \mathrm{C}$ demonstrou que o corpo da lata manteve a classificação média $9 \mathrm{G}$ (alteração em até 0,03\% da área) por todo o período de estocagem, enquanto a tampa atingiu 8G (alteração em até 0,1\% da área) e o fundo atingiu média $7 \mathrm{G}$ (alteração em até 0,3\% da área). As alterações foram identificadas como pequeno aumento na incidência de alguns pontos de oxidação ao longo do período de estocagem. A região de soldagem sofreu alteração um pouco maior, aumentando progressivamente a região com desestanhamento nas laterais do cordão de solda, sendo que aos 720 dias equivalia ao grau 3G (alteração em até $1 \%$ da área). Considerando-se a avaliação média da lata como um todo, mesmo aos 720 dias de estocagem a lata de extrato de tomate apresentava classificação 7G, bem acima da metade da escala, correspondente ao grau $5 \mathrm{G}$. Nas latas referência, avaliadas quando do término de seu prazo de validade, após estocagem à temperatura ambiente, reproduzindo a condição normal de utilização, praticamente não se observou alteração no corpo, na tampa e no fundo, enquanto que, na região de soldagem, ocorreu desestanhamento na lateral do cordão de solda, de forma similar ao observado nas latas com camada de estanho de 2,0 g.m-2, estocadas em condição de temperatura mais elevada. A Figura 1 ilustra a aparência do corpo e da região de soldagem das embalagens.

\subsection{Quantificação de ferro, estanho e cromo no produto}

A concentração de ferro no período de 720 dias apresentou-se $332 \%$ superior à concentração observada na lata referência no término do prazo de validade (Tabela 3). Apesar do efeito da maior temperatura de estocagem utilizada nas latas com corpo em folha de flandres 2,0 g.m $\mathrm{m}^{-2}$, a diferença observada evidencia que o tipo de folha metálica também exerceu influência na intensidade de oxidação observada. Adotando-se o desempenho da lata referência como adequado, uma vez que é um produto de mercado, a sua concentração de ferro no término do prazo de validade foi tomada como parâmetro esperado para a lata em estudo. A regressão dos dados permitiu o estabelecimento de um modelo exponencial para a concentração de ferro no extrato de tomate em função da temperatura de estocagem, conforme equação apresentada na Figura 2, regressão essa significativa no nível de erro de 5\%.

A Legislação Brasileira estabelece como $250 \mathrm{mg} \mathrm{kg}^{-1}$ e 0,10 mg. $\mathrm{kg}^{-1}$ (BRASIL, 1998) e (BRASIL, 1965), os teores máximos de estanho e cromo, respectivamente, para produtos em geral. Assim, os valores encontrados para estanho, na lata com camada de estanho de 2,0 g.m ${ }^{-2}$

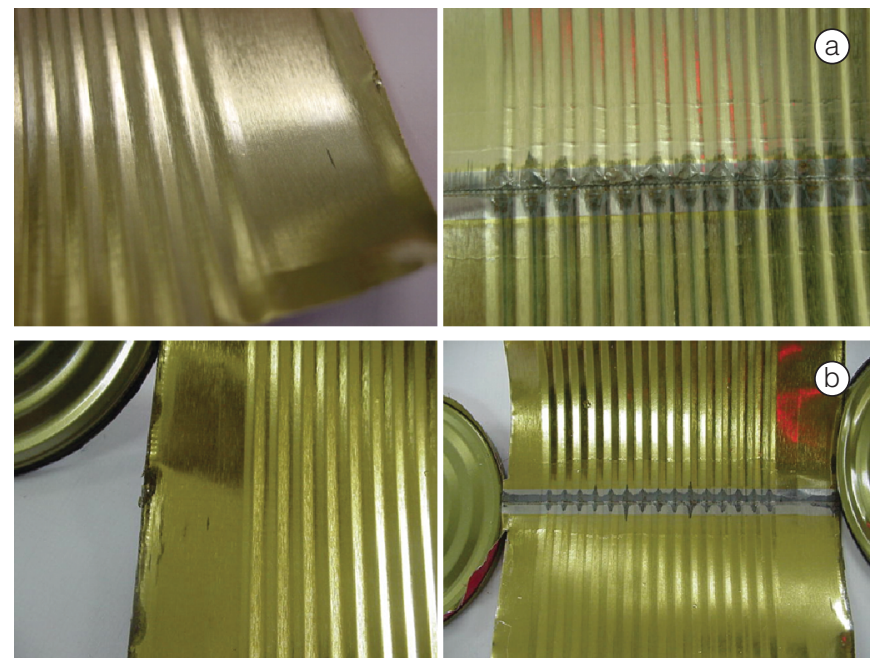

Figura 1. Fotografias do corpo e da região de soldagem das latas de extrato de tomate após estocagem: (a) lata com corpo em folha de flandres 2,0 g. $\mathrm{m}^{-2}$, (b) lata referência.

Tabela 2. Resultados de camada seca, grau de cura e aderência no verniz interno de corpo, tampa, fundo e side stripe da lata de extrato de tomate.

\begin{tabular}{lcccc}
\multicolumn{1}{c}{ Parâmetro } & \multicolumn{2}{c}{ Lata de extrato de tomate } \\
& Corpo & Tampa & Fundo & Side Stripe \\
\hline Camada seca $\left(\mathrm{g} \cdot \mathrm{m}^{-2}\right)^{(1,2)}$ & $12,5 \pm 1,0$ & $4,9 \pm 0,2$ & $5,8 \pm 0,4$ & $9,1 \pm 1,4$ \\
Grau de cura $\left(\mathrm{n}^{\circ} \text { de ciclos) }\right)^{(2,4)}$ & 27 & 32 & 52 & 50 \\
Aderência (graus) & $5 \mathrm{~B}$ & $5 \mathrm{~B}$ & $5 \mathrm{~B}$ & $4 \mathrm{~B}$ \\
Porosidade de verniz interno (mA/lata ou tampa) $)^{(1,3)}$ & $47,6 \pm 13,9$ & $9,5 \pm 9,9$ & $(5)$ & $(5)$ \\
\hline
\end{tabular}

${ }^{(1)}$ Média \pm desvio padrão. ${ }^{(2)}$ Resultado de 5 determinações. ${ }^{(3)}$ Resultado de 10 determinações. ${ }^{(4)}$ Solvente metil etil cetona. ${ }^{(5)}$ Resultado apresentado em conjunto com o corpo da lata. 


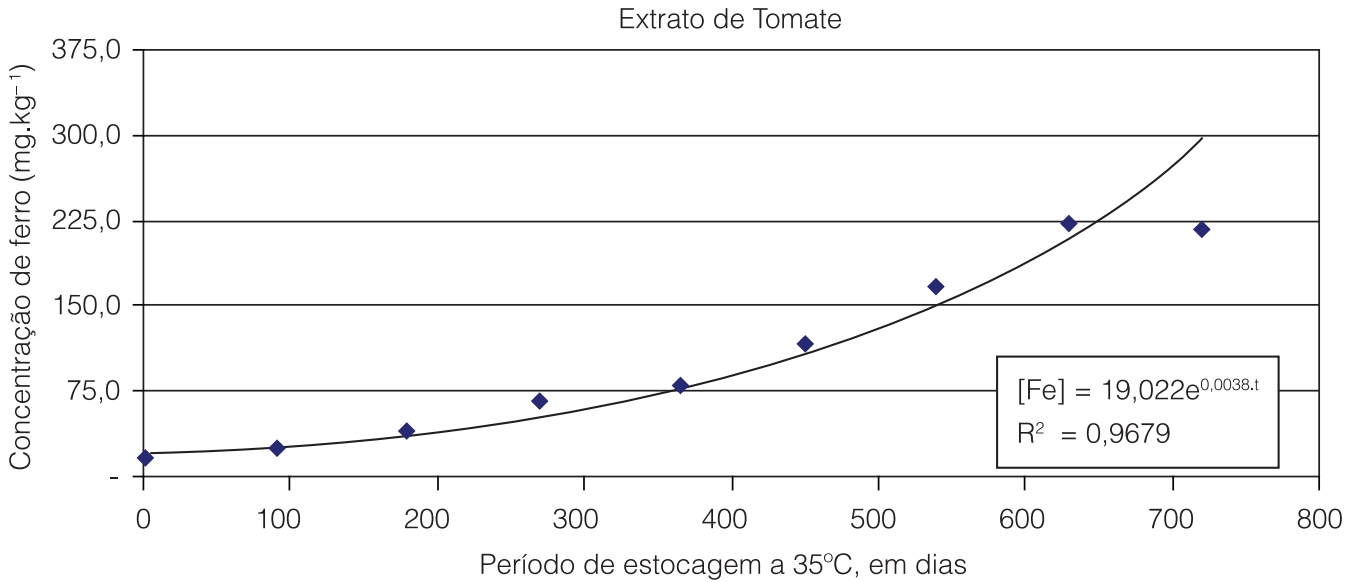

Figura 2. Concentração de ferro, em mg. $\mathrm{kg}^{-1}$, no extrato de tomate acondicionado ao longo de 720 dias de estocagem a $35^{\circ} \mathrm{C}$.

Tabela 3. Concentração de ferro, estanho e cromo no extrato de tomate, em função do tempo de estocagem à temperatura de $35^{\circ} \mathrm{C}$, e no produto da lata referência estocada no ambiente ao término do prazo de validade, em $\mathrm{mg} \cdot \mathrm{kg}^{-1(1)}$.

\begin{tabular}{|c|c|c|c|c|}
\hline \multicolumn{2}{|c|}{ Tempo de estocagem (dias) } & Ferro & Estanho & Cromo \\
\hline \multirow[t]{3}{*}{0} & Média & $15,43^{a}$ & $0,18^{a}$ & $0,28^{\mathrm{ac}}$ \\
\hline & Desvio padrão & 2,20 & 0,03 & 0,03 \\
\hline & Intervalo de variação & $12,99-18,55$ & $0,13-0,22$ & $0,25-0,34$ \\
\hline \multirow[t]{3}{*}{90} & Média & $24,39 \mathrm{ab}$ & $0,25^{\mathrm{ab}}$ & $0,26^{\mathrm{ab}}$ \\
\hline & Desvio padrão & 3,29 & 0,02 & 0,03 \\
\hline & Intervalo de variação & $20,51-29,54$ & $0,22-0,28$ & $0,23-0,30$ \\
\hline \multirow[t]{3}{*}{180} & Média & $40,45^{b}$ & $0,33^{b}$ & $0,24^{b}$ \\
\hline & Desvio padrão & 4,24 & 0,10 & 0,01 \\
\hline & Intervalo de variação & $36,27-44,93$ & $0,23-0,50$ & $0,23-0,26$ \\
\hline \multirow[t]{3}{*}{270} & Média & $67,27^{\circ}$ & $0,33^{b}$ & $0,26^{b}$ \\
\hline & Desvio padrão & 5,19 & 0,07 & 0,01 \\
\hline & Intervalo de variação & $61,62-74,30$ & $0,24-0,44$ & $0,25-0,28$ \\
\hline \multirow[t]{3}{*}{365} & Média & $80,84^{c}$ & $0,30^{\mathrm{ab}}$ & $0,25^{\mathrm{ab}}$ \\
\hline & Desvio padrão & 10,15 & 0,05 & 0,01 \\
\hline & Intervalo de variação & $66,63-93,40$ & $0,22-0,37$ & $0,23-0,27$ \\
\hline \multirow[t]{3}{*}{450} & Média & $116,10^{d}$ & $0,69^{c}$ & $0,37^{c}$ \\
\hline & Desvio padrão & 7,20 & 0,20 & 0,05 \\
\hline & Intervalo de variação & $105,65-122,08$ & $0,45-0,92$ & $0,30-0,44$ \\
\hline \multirow[t]{3}{*}{540} & Média & $168,03^{e}$ & $0,26^{\mathrm{ab}}$ & $0,27^{\mathrm{ab}}$ \\
\hline & Desvio padrão & 33,13 & 0,06 & 0,02 \\
\hline & Intervalo de variação & $130,39-220,93$ & $0,19-0,32$ & $0,24-0,29$ \\
\hline \multirow[t]{3}{*}{630} & Média & $221,70^{f}$ & $0,17^{a}$ & $0,30^{a}$ \\
\hline & Desvio padrão & 32,31 & 0,15 & 0,01 \\
\hline & Intervalo de variação & $181,07-266,42$ & $0,08^{(2)}-0,43$ & $0,29-0,31$ \\
\hline \multirow[t]{3}{*}{720} & Média & $218,05^{f}$ & $0,23^{a b}$ & $0,26^{b}$ \\
\hline & Desvio padrão & 29,09 & 0,11 & 0,02 \\
\hline & Intervalo de variação & $175,82-246,00$ & $0,08^{(2)}-0,37$ & $0,24-0,29$ \\
\hline \multirow[t]{3}{*}{ Lata referência ${ }^{(3)}$} & Média & 65,98 & 1,14 & 0,16 \\
\hline & Desvio padrão & 6,48 & 0,10 & 0,01 \\
\hline & Intervalo de variação & $60,14-76,95$ & $0,97-1,22$ & $0,15-0,17$ \\
\hline
\end{tabular}

(1)Resultado de três determinações em cinco unidades de latas. (2)Limite de quantificação do método nas condições analíticas utilizadas. ${ }^{\left({ }^{(3)} L a t a\right.}$ referência avaliada após manutenção em condição de temperatura ambiente até o término do prazo de validade. $a, b, c, d, e, f$ Médias acompanhadas pela mesma letra, na mesma coluna, não diferem significativamente entre si pela análise de variância no nível de erro de $5 \%$, em relação ao tempo de estocagem. 
e na lata referência, nos períodos estudados, estão abaixo do limite estabelecido pela Legislação Brasileira. Para o cromo, foram encontrados valores superiores ao limite máximo da legislação, em ambas as amostras. Entretanto, provavelmente essa concentração de cromo seja decorrente da matéria-prima e/ou do processamento do produto, não estando necessariamente relacionada à interação produto/embalagem durante o período de estocagem, pois o teor de cromo na época de zero dia já se apresentava superior a $0,10 \mathrm{mg} \cdot \mathrm{kg}^{-1}$ e não houve variação importante ao longo do tempo.

Segundo a literatura, o extrato de tomate apresenta conteúdo de ferro de $21 \mathrm{mg} \cdot \mathrm{kg}^{-1}$ (ppm), conforme apresentado na Tabela de Composição de Alimentos (UNICAMP, 2006), sendo que o teor observado inicialmente neste estudo encontrava-se inferior ao descrito na referida tabela. Em decorrência do processo de oxidação da embalagem, principalmente na região de soldagem, a concentração de ferro na lata em estudo aumentou cerca de 14 vezes ao longo do período de estocagem e a lata referência apresentava, no final do prazo de validade, teor de ferro aproximadamente três vezes superior ao valor teórico, de acordo com a Tabela de Composição de Alimentos.

A Legislação Brasileira não estabelece limite para o ferro no produto em estudo, visto que é um elemento essencial à dieta humana. Entretanto, o aumento da concentração desse elemento evidencia o desenvolvimento de oxidação da embalagem, resultando na redução do vácuo e, possivelmente, na alteração do sabor do produto acondicionado.

\subsection{Determinação do volume e da composição gasosa do espaço livre}

As médias e os desvios padrão dos resultados da determinação ao zero dia e aos 810 dias de estocagem a $35{ }^{\circ} \mathrm{C}$ do volume gasoso e da composição de $\mathrm{O}_{2}$, $\mathrm{H}_{2}, \mathrm{CO}_{2}$, e $\mathrm{N}_{2}$ são apresentados na Tabela 4, tendo-se apresentado significativamente diferentes no nível de erro de $5 \%$. A concentração de $\mathrm{O}_{2}$ ao zero dia e no término do período de estocagem considerado (90 dias superior ao da vida útil estabelecida para o produto) sofreu grande aumento, demonstrando ter havido desenvolvimento de oxidação interna; o aumento observado na concentração de $\mathrm{CO}_{2}$ é explicado pelas reações inerentes ao produto. A variação na concentração de oxigênio não era esperada e provavelmente decorra da variabilidade das unidades avaliadas, uma vez que a presença em concentração relevante do gás hidrogênio evidencia que houve desenvolvimento de corrosão, em cuja reação o oxigênio é consumido. A concentração de nitrogênio foi obtida pelo balanço dos gases presentes e, portanto, sua variação porcentual decorre do aumento do volume gasoso na embalagem.

\subsection{Determinação do vácuo/pressão positiva}

A Figura 3 ilustra a evolução da pressão interna nas latas de extrato de tomate ao longo dos 720 dias de estocagem a $35^{\circ} \mathrm{C}$, bem como da lata referência. Observou-se que, aos 450 dias de estocagem, as latas apresentavam pressão interna positiva, em razão da produção de $\mathrm{H}_{2}$ em consequência da oxidação interna da lata - a formação de gás hidrogênio decorre da reação de redução catódica do hidrogênio presente no meio ácido: $2 \mathrm{H}^{+}+2 \mathrm{e}^{-} \rightarrow \mathrm{H}_{2}-$ e do aumento de $\mathrm{CO}_{2}$ em função de reações inerentes ao produto. A partir dessa época, todas as latas apresentaram pressão interna positiva, a qual evoluiu gradativamente até os 720 dias de estocagem. A amostra referência apresentava vácuo de 1,52 pol Hg ao término do tempo de estocagem, mostrando-se em condição praticamente limite. A regressão linear de perda de vácuo [Vácuo (psi) = 0,011.t (em dias) + 4,227, $\left.\mathrm{R}^{2}=0,9512\right]$ permite a estimativa do tempo para atingir o valor de vácuo nulo, que corresponde a 394 dias.

Em estudo realizado em latas de extrato de tomate de capacidade de $140 \mathrm{~g}$ com revestimento de estanho na face interna equivalente a $5,6 \mathrm{~g} \cdot \mathrm{m}^{-2}$ e verniz na costura eletrossoldada do tipo epóxi ureia, pelo período de 12 meses, em três condições de temperatura de estocagem $\left(23^{\circ} \mathrm{C}, 30^{\circ} \mathrm{C}\right.$ e $\left.35^{\circ} \mathrm{C}\right)$, foi observada a concentração média de ferro aos 365 dias de 72,84 $\mathrm{mg} \mathrm{kg}^{-1}$, 97,16 $\mathrm{mg} \mathrm{kg}^{-1} \mathrm{e}$ 223,46 $\mathrm{mg} \mathrm{kg}^{-1}$, respectivamente; permitiu-se, dessa forma, o estabelecimento do índice $Q_{10}$, que representa o efeito de redução da vida útil do produto, com base na dissolução de ferro, para o aumento de $10{ }^{\circ} \mathrm{C}$ na temperatura de estocagem, de 1,31 para o extrato de tomate (DANTAS, 1998). Assim, comparando-se a concentração de ferro no produto da lata referência de mercado e da lata com folha de flandres 2,0 $\mathrm{g} \cdot \mathrm{m}^{-2}$,

Tabela 4. Resultados médios do volume, em $\mathrm{mL}$, e da composição de $\mathrm{O}_{2}, \mathrm{H}_{2}, \mathrm{CO}_{2}$ e $\mathrm{N}_{2}$ presentes no espaço livre da lata contendo extrato de tomate, em porcentagem ${ }^{(1)}$.

\begin{tabular}{|c|c|c|c|c|c|}
\hline \multirow{2}{*}{ Tempo de estocagem } & \multirow{2}{*}{ Volume gasoso $(\mathrm{mL})$} & \multicolumn{4}{|c|}{ Porcentagem de gás (v/v) } \\
\hline & & $\mathbf{O}_{2}$ & $\mathrm{H}_{2}$ & $\mathrm{CO}_{2}$ & $\mathbf{N}_{2}$ \\
\hline Zero dia ${ }^{2}$ & $6,7^{\mathrm{a}} \pm 3,7$ & $0,3^{a} \pm 0,1$ & $6,2^{a} \pm 1,4$ & $4,6^{a} \pm 0,1$ & $89,4^{a} \pm 1,3$ \\
\hline 810 dias a $35^{\circ} \mathrm{C}^{3}$ & $28,0^{\mathrm{b}} \pm 8,1$ & $0,8^{b} \pm 0,1$ & $49,3^{b} \pm 22,1$ & $6,7^{b} \pm 0,5$ & $19,9^{b} \pm 2,5$ \\
\hline
\end{tabular}

${ }^{(1)}$ Média \pm desvio padrão. ${ }^{(2)}$ Resultado de quatro determinações. ${ }^{(3)}$ Resultado de três determinações. ${ }^{a, b}$ em uma mesma coluna, médias seguidas pela mesma letra não diferem estatisticamente entre si, pelo Teste da Mínima Diferença Significativa, no nível de erro de 5\%. 


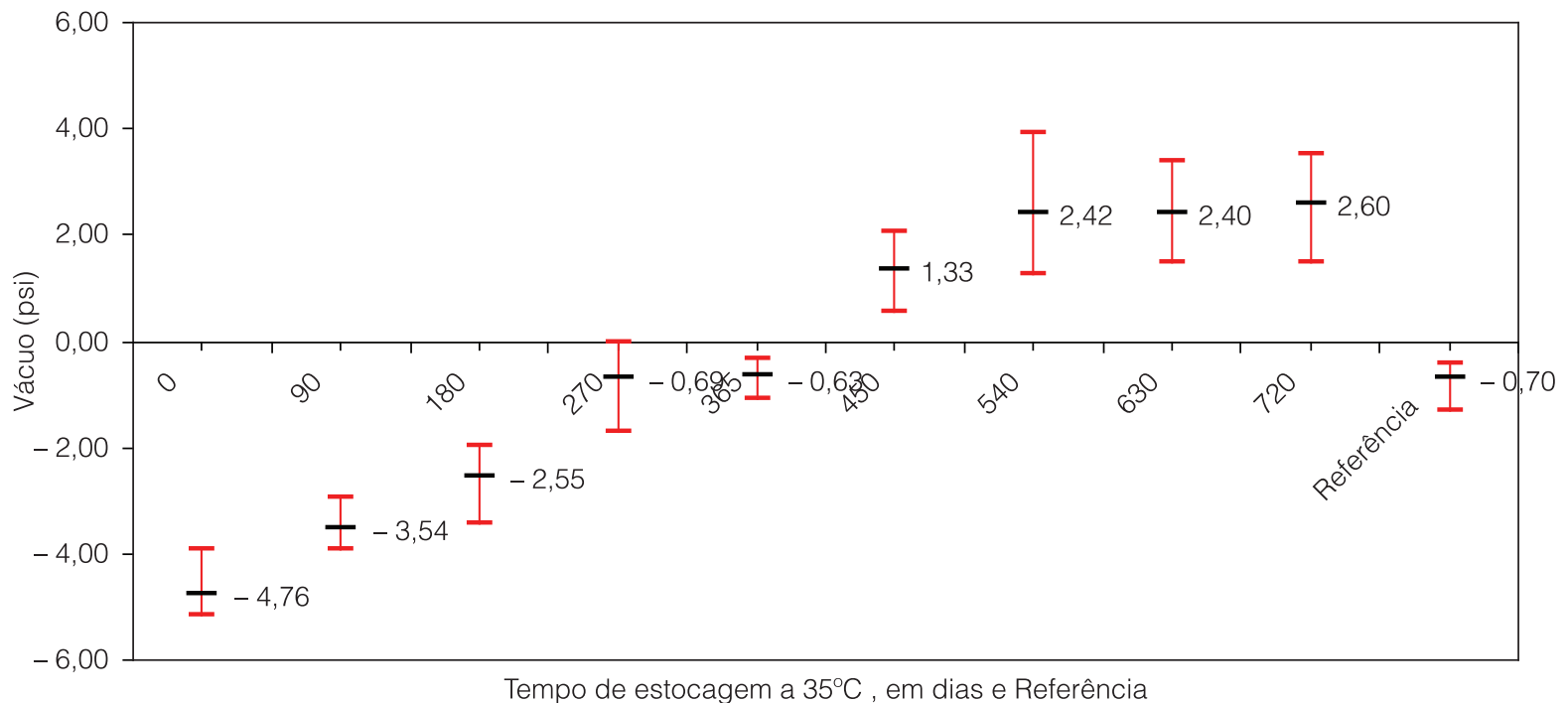

Figura 3. Evolução da pressão interna média das latas de extrato de tomate com camada de estanho de $2,0 \mathrm{~g} \cdot \mathrm{m}^{-2}$ durante estocagem a $35^{\circ} \mathrm{C}$ por 24 meses e da lata referência ao término do prazo de validade $(1 \mathrm{psi}=2,04 \mathrm{polHg})$.

em ambas, após o término do período de validade considerado, de 2 anos, observa-se que o resultado demonstra que houve um efeito adicional ao do aumento da temperatura na dissolução do ferro.

Considerando-se 394 dias de vida-de-prateleira (estabelecido pelo tempo até a lata atingir vácuo nulo), a dissolução de ferro estimada, utilizando-se a regressão da Figura 1, é de $85,0 \mathrm{mg} \cdot \mathrm{kg}^{-1}$ a $35^{\circ} \mathrm{C}$. Com base no índice $Q_{10}$ obtido em Dantas (1998), a dissolução de ferro correspondente aos 394 dias de estocagem a $25^{\circ} \mathrm{C}$ seria de $64,9 \mathrm{mg} \cdot \mathrm{kg}^{-1}$, sendo $1,7 \%$ inferior à concentração de ferro determinada na lata referência $\left(65,98 \mathrm{mg} \cdot \mathrm{kg}^{-1}\right)$, que ficou estocada à temperatura ambiente até o vencimento do prazo de validade estabelecido na embalagem. De maneira similar, assumindo como 85,0 mg. $\mathrm{kg}^{-1}$ a concentração limite para a ocorrência de vácuo nulo na estocagem a $35^{\circ} \mathrm{C}$, é possível estimar, para a estocagem a $25^{\circ} \mathrm{C}$, o prazo de 465 dias para que o produto atinja essa mesma condição (vácuo nulo).

\section{Conclusões}

De acordo com os resultados obtidos, foi possível observar que houve alteração não desprezível em relação à dissolução de metais da lata para o produto, com a consequente perda de vácuo; esta atingiu condição inaceitável aos 450 dias de estocagem, a partir de quando as latas passaram a apresentar pressão interna positiva. Considerando-se uma regressão linear de perda de vácuo, a estimativa para atingir o valor de vácuo nulo foi de 394 dias (13 meses). Assim, em decorrência da interação com a embalagem, para a estocagem a $35^{\circ} \mathrm{C}$, a lata com corpo em folha de flandres com revestimento de estanho de 2,0 g. $\mathrm{m}^{-2}$ e condições de envernizamento avaliadas neste estudo não é indicada na utilização para o acondicionamento de extrato de tomate, levando-se em conta o prazo de validade atualmente aplicado para esse produto, ou seja, de dois anos.

Com base nas condições avaliadas no presente estudo, conclui-se que a lata avaliada é uma opção viável e segura de embalagem para o acondicionamento de $350 \mathrm{~g}$ de extrato de tomate por 394 dias (13 meses) de estocagem, na temperatura média de até $35^{\circ} \mathrm{C}$.

\section{Agradecimentos}

À Metalúrgica Mococa S/A, pelo suporte financeiro.

\section{Referências}

AMERICAN SOCIETY FOR TESTING AND MATERIALS - ASTM. D 610-08: Standard Test Method for Evaluating Degree of Rusting on Painted Steel Surfaces. Philadelphia: ASTM INTERNATIONAL, 2008a. 6 p.

AMERICAN SOCIETY FOR TESTING AND MATERIALS - ASTM. D 3359-08: Standard Test Method for Measuring Adhesion by Tape Test. Philadelphia: ASTM INTERNATIONAL, 2008b. 7 p.

ASSOCIAÇÂO BRASILEIRA DE NORMAS TÉCNICAS - ABNT. NBR 6665: Folhas Laminadas de Aço-Carbono Revestidas Eletroliticamente com Estanho ou Cromo ou Não Revestidas - Especificação. Rio de Janeiro: ABNT, 2010. 23 p.

BRASIL. Agência Nacional de Vigilância Sanitária. Resolução RDC n² 20 de 22 de março de 2007. Aprova o regulamento técnico sobre disposições para embalagens, revestimentos, utensílios, tampas e equipamentos metálicos em contato com alimentos. Diário Oficial da República Federativa do Brasil, Brasília, DF, 26 mar. 2007. Disponível em: <http://elegis.anvisa. gov.br/leisref/public/showAct. php?id=26268\&word $>$. Acesso em: 25 maio. 2009. 
Estabilidade de extrato de tomate em embalagens metálicas com baixo revestimento de estanho DANTAS, S. T. et al.

BRASIL. Secretaria de Vigilância Sanitária. Decreto n 55871 , de 26 de março de 1965. Limite máximo de contaminantes inorgânicos em alimentos. Diário Oficial da República Federativa do Brasil, Brasília, DF, 28 mar. 1965. Disponível em: <http://www.dou.gov.br>. Acesso em: 25 jul. 2005.

BRASIL. Secretaria de Vigilância Sanitária. Portaria n 685, de 27 de agosto de 1998. Princípios gerais para o estabelecimento de níveis máximos de contaminantes químicos em alimentos. Diário Oficial da República Federativa do Brasil, Brasília, DF, ago. 1998. Seção 1, 4 p. Disponível em: <http://www.dou.gov. br>. Acesso em: 25 jul. 2005.

DANTAS, S. T.; ANJOS, V. D. A.; SEGANTINI, E.; GATTI, J. A. B. Avaliação da Qualidade de Embalagens Metálicas: Aço e Alumínio. Campinas: ITAL/CETEA, 1996. 317 p.

DANTAS, S.T. Estudo de latas eletrossoldadas para acondicionamento de ervilhas, extrato de tomate e pêssego em calda. 1998. 197 f. Tese (Doutorado em Tecnologia de Alimentos)-Universidade Estadual de Campinas, Campinas, 1998.

DANTAS, S.T. Avaliação do processo de interação e estudos de estabilidade. In: DANTAS, S. T.; GATTI, J. A. B.; SARON, E. $S$. Embalagens Metálicas e a Sua Interação com Alimentos e Bebidas. Campinas: CETEA/ITAL, 1999. cap. 10, p. 173-188.

DANTAS, S. T.; GATTI, J. A. B.; SARON, E. S. Estudo da viabilidade de redução da camada de estanho em latas para palmito. In: CONGRESSO BRASILEIRO DE CIÊNCIA E TECNOLOGIA DE
ALIMENTOS, 15., 2000, Fortaleza. Resumos... Fortaleza, 2000. v. 1, p. 6.

FARIA, E. V. Avaliação do Desempenho de Latas de Folha de Flandres por Meio da Espectroscopia de Impedância Eletroquímica e do Acompanhamento da Estocagem de Palmito Pupunha (Bactris Gasipaes). 2000. 168 f. Tese (Doutorado em Engenharia Mecânica)-Universidade Estadual de Campinas, Campinas, 2000.

INTERNATIONAL ORGANIZATION FOR STANDARDIZATION. ISO 11950: Cold-Reduced Electrolytic Chromium/Chromium Oxide-Coated Steel. Geneva: ISO, 1995. 22 p.

PERRING, L.; BASIC-DVORZAK, M. Determination of total tin in canned food using inductively coupled plasma atomic emission spectroscopy. Analytical and Bioanalytical Chemistry, Heidelberg, v. 374, n. 2, p. 235-243, 2002. http://dx.doi. org/10.1007/s00216-002-1420-x

SARON, E. S.; DANTAS, S. T.; KIYATAKA, P. H. M.; MENEZES, H. C.; SOARES, B. M. C. Viabilidade da redução da camada de estanho em latas de aço para suco de maracujá pronto para beber. Brazilian Journal of Food Technology, Campinas, v. 9, n. 4, p. 283-290, out./dez. 2006.

STATSOFT COMPANY. Statistica 5.0. Tulsa: StatSoft Inc., 1995. UNIVERSIDADE ESTADUAL DE CAMPINAS - UNICAMP. Tabela Brasileira de Composição de Alimentos - Taco. versão 2. 2. ed. Campinas: UNICAMP/NEPA, 2006. 114 p. Disponível em: <http://www.unicamp.br/nepa/taco/contar/ taco_versao2.pdf>. Acesso em: 02 dez. 2008. 